\title{
Quantitative assessment of plant water consumption in the summer after creating a green curtain by using ivy morning glory on a south- facing wall
}

\author{
Naru TAKAYAmA*, ${ }^{\dagger}$, Koji KAWAMURA*, Haruhiko YAMAMOTO**, Shohei NOBORI***, \\ and Yosuke TOMINAGA**** \\ * Faculty of Engineering, Osaka Institute of Technology, Osaka, 535-8585, Japan \\ ** Faculty of Agriculture, Yamaguchi University, Yamaguchi, 753-8515, Japan \\ *** Nishimura Fukoen, 65, Asahimachi, Himeji, Hyogo, 670-0934, Japan \\ **** TOHO LEO, 1-1-28, Uemachi, Chuoku, Osaka, 540-0005, Japan
}

\begin{abstract}
In this study, wall greening with vines was constructed using a simple net on a south wall, and the water consumption of the plants was evaluated. A model to estimate the water requirement for wall greening was proposed in which weather conditions and plant growth were considered as explanatory variables. From August 20, 2011 to October 2, 2011, the mean daily water consumption was $18.4 \mathrm{~mm}$, the estimated total water consumption was $1.8 \mathrm{~m}^{3}$ and the mean leaf area per unit of ground $\left(L A I_{g}\right)$ was 11.0. We defined the ratio of water consumption to the maximum value as the standard ratio of water consumption, and estimated the daily standard water consumption rate with our model that uses several climatological factors and $L A I_{g}$ as explanatory variables. The mean absolute error for the estimation was $6.1 \%$, suggesting that the water consumption of the wall greening could be evaluated quantitatively through investigation of the water balance of plants.
\end{abstract}

Key words: Heat island, Ivy morning glory, Standard water consumption rate, Wall greening, Water consumption.

\section{Introduction}

Roof and wall greening in urban areas with little available space have been promoted by various measures including subsidies by local governments, property tax reduction and the distribution of plant materials. These efforts have been performed in order to create beautiful urban spaces as well as mitigate the heat island effect. According to a national Japanese survey on roof and wall greening areas (Ministry of Land, Infrastructure, Transport and Tourism, 2012), the total area used for roof and wall greening in 2010 was at least 343.5 ha since 2000.

Wall greening using climbing plants (i.e., 'green

Received; March 5, 2013.

Accepted; November 12, 2013.

${ }^{\dagger}$ Corresponding Author: tnaru@env.oit.ac.jp

DOI: 10.2480/agrmet.D-13-00007 curtains') has become increasingly popular in recent years as a simple and cost-effective way to create green walls on regular households. This type of greening represented $81.3 \%$ whole of all wall greening implemented in 2010. Since the shutdown of nuclear power plants after the Tohoku Earthquake in March 2011 has strained power supplies and demand during the summer, household green curtains have spread rapidly as a way to save energy. Green curtains have two known heat-reduction functions: the 'cooling effect' through the consumption of latent heat by plant evapotranspiration and the 'umbrella effect' achieved by blocking solar radiation and thus decreasing the amount of net radiation absorbed by the building. These effects have improved the indoor and outdoor thermal environments during the summer by reducing the walls' increases in temperature (Todo et al., 2008). We have evaluated the amount of heat-load reduction achieved by wall greening with ivy morning glory 
during summer days. Ivy morning glory increased in popularity in recent years as a suitable plant that is suitable for green curtains. In those our study, an elementary school with green walls on the south side exhibited a reduction in total thermal load during the day by $75 \%$ to $78 \%$ (Takayama et al., 2011, 2012).

Although wall greening is useful for mitigating heat, the spread of greenery in urban areas generates an increased demand for water resources. According to Suzuki et al. (2007), the amount of evapotranspiration from a green wall panel system that could be used for planting greenery in urban spaces was about $4.1 \mathrm{~mm}$ day $^{-1}$. It was reported in the 10 -Year Project for Green Tokyo (Tokyo Metropolitan Government, 2012), that urban greening on walls and rooftops created 91.9 ha of greenery over a period of 4 years since 2007. Assuming a daily evapotranspiration of $4.1 \mathrm{~mm}, 347,000$ $\mathrm{m}^{3}$ of water consumption might be newly generated during the summer (i.e. July to September) in this case. The amount of available water resources per person in Japan is $8.8 \mathrm{~m}^{3} /$ day (38\% of the world average) only $27 \%$ of which (10\% of the world average) goes to people in the metropolitan areas (Ministry of Land, Infrastructure, Transport and Tourism, 2011). While urban green space has been steadily increased in recent years, it is necessary to quantitatively assess the waterconsumption needs of urban greening plants in order to manage precious water resources.

It is desirable to build greening walls that do not require irrigation but instead use available rainwater (Urban Greenery Technology Development Organization, 1996). Realistically, however, to create wall greening (e.g., by using planter boxes or by planting panels with artificial soil on balconies), installing efficient irrigation equipment is essential to maintaining sufficient plant growth (Suzuki et al., 2005). In this study, we implemented climber-type wall greening on a south wall and assessed the water balance of planter boxes and the water consumption of plants. As a result, we have proposed a method for estimating water consumption that accounts for environmental factors such as plant growth and weather conditions.

\section{Materials and Methods}

\subsection{Implementation of wall greening as an experi- mental subject}

Climber-type wall greening (i.e., green curtain) was implemented on the south wall terrace at the east end of the sixth floor of a seven-story concrete structure at Osaka Institute of Technology in Omiya, Asahi-ku, Osaka City, Osaka Prefecture (hereafter referred to as 'the green room'). On June 7, 2011, we prepared five wooden, water-storing, cistern-type planter boxes (Sewairazu, Nissan Greening Co.) with the dimensions $36 \mathrm{~cm} \times 76 \mathrm{~cm}$ wide $\times 37 \mathrm{~cm}$ and 13 plastic, commercially available gardening pots $(13.5 \mathrm{~L}, 28 \mathrm{~cm}$ in diameter). We planted five stalks of ivy morning glory (Ipomoea indica $\mathrm{cv}$.) in each planter box. Each stalk was planted in a gardening pots (i.e., 38 stems total). Soil was adjusted to $10 \mathrm{~L}$ /plant. The planter boxes and gardening pots were placed on the sixth floor south wall terrace, and a net $(10 \mathrm{~cm}$ grid, $3.6 \mathrm{~m} \times$ $6.0 \mathrm{~m}$ ) was hung from the seventh floor terrace. The vines of the ivy morning glory coiled around the net and reached to the seventh floor. The height of the greening area was $4.24 \mathrm{~m}$. Figure 1 shows the experimental setup on the south terrace wall. A sufficient amount of water was supplied to the planter boxes and gardening pots by using an automatic irrigation system. Liquid fertilizer (Sumitomo liquid fertilizer No. 1, Sumitomo Chemical Co.) was periodically supplied to all planters.

\subsection{Measurement of water consumption by planter boxes}

To evaluate water consumption, we constructed the apparatus on two units of planter boxes (Fig. 2). Changes in the water level in the irrigation water supply tank and the cistern, as well as changes in the volumetric water content of the soil were measured rou-

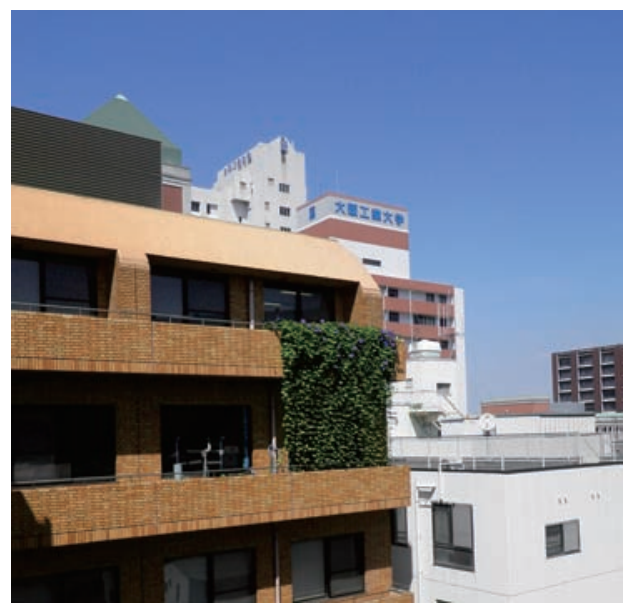

Fig. 1. Experimental setup on the south terrace wall. 
tinely. Soil in the planter boxes was watered for 10 to 30 minutes twice a day (i.e., at 5 and $7 \mathrm{pm}$ ) from the supply tank that had a capacity of 20 L. Two Polyvinyl chloride pipes $(\varphi=48 \mathrm{~mm})$ passed through the bottom plate of the planter box below the soil, and reached the cistern whose maximum depth was $17 \mathrm{~cm}$. Since, there were also several holes in the bottom plate of the planter box below the soil, water that infiltrated to the bottom of the soil flowed into the cistern. In dry conditions, the absorption of water from the cistern to the rhizosphere occurred naturally through the PVC pipes. A pressure-type water-level sensor (PR-46X, Keller; Winterthur; Switzerland) was inserted into the irrigation water supply tank and the cistern. The water level was measured at intervals of $10 \mathrm{~s}$, and we calculated the moving average from values recorded 5 minutes before and after the per-minute time point. The soil volumetric water content was measured at intervals of 2 minutes with a soil moisture meter (ECHO-10, Decagon; Pullman; U.S.A.). A soil moisture meter was buried perpendicular to the soil surface, and since its length was equal to the soil depth, the measured values should have indicated the representative volumetric water content of the soil. Rainwater that blew onto the terrace was measured with a tipping-bucket rain gauge.

\subsection{Weather observation}

We performed weather observations from September 26 to August 20, 2011. The observed meteorological elements included air temperature $\left({ }^{\circ} \mathrm{C}\right)$, relative humidity (\%), wind speed $\left(\mathrm{m} \mathrm{s}^{-1}\right)$, and solar radiation of the wall $\left(\mathrm{W} \mathrm{m}^{-2}\right)$. Air temperature and relative humidity were measured at intervals of 2 minutes with TR-71U (T\&D Corp.; Matsumoto; Japan), and the moving average was calculated from values recorded 4 minutes before and after each time point. Wind speed and solar radiation were measured at intervals of $10 \mathrm{~s}$ with SonicWind (Gill Instruments Ltd.; Lymington; UK) and CHF-LP02 (Hukseflux; Delft; Netherland), respectively. The moving average was calculated from values recorded 5 minutes before and after the perminute time point.

\subsection{Measurement of leaf area of wall-greening plants}

During the experimental period, we constructed a frame $(30 \mathrm{~cm} \times 30 \mathrm{~cm})$ on the greening wall on the sixth floor of the building and counted the number of leaves in the frame four times (i.e., on August 9, August 23, September 28, and October 11). At the same time, the length and width of each leaf were measured with a ruler. Another frame was similarly constructed

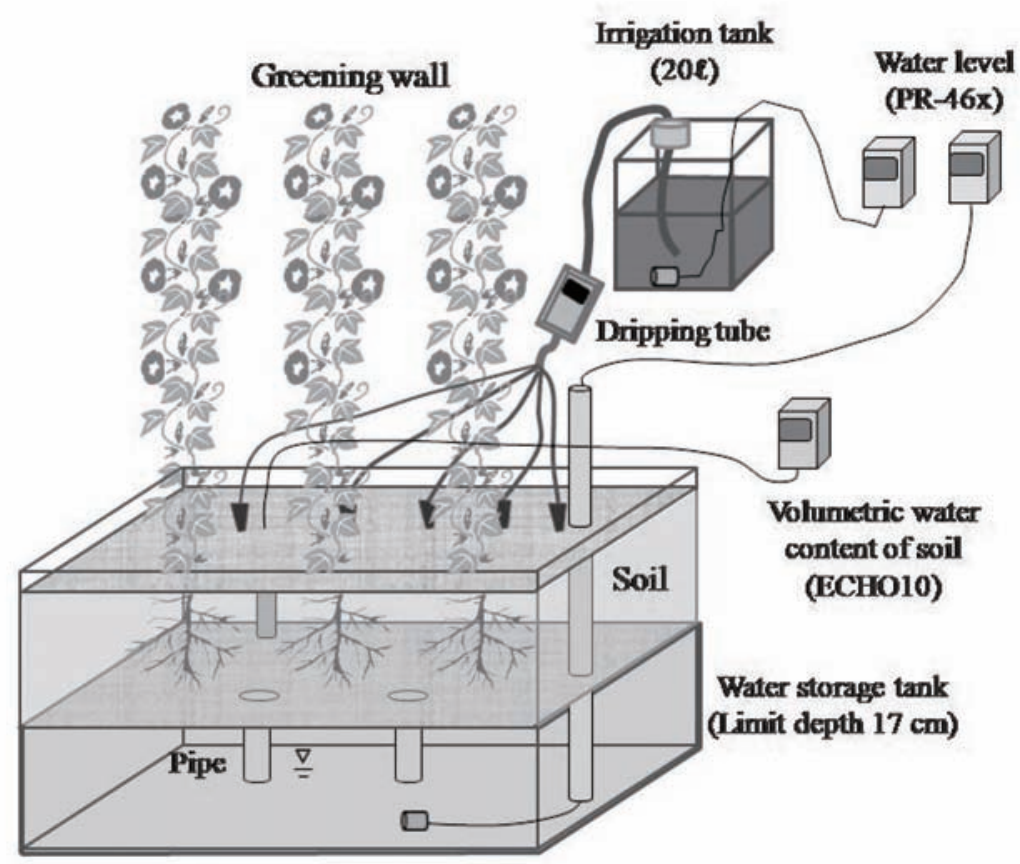

Fig. 2. Schematic of the water balance observation system using a water-storing cistern-type planter box. 
on September 13 on the seventh floor of the building, and all leaves in the frame were sampled. The sampled leaves were read by a scanner, and the length and width of each leaf (i.e., individual leaf area) were measured using LIA32 analysis software (Yamamoto, 2010). On November 4, the last day of the experiment, we sampled all leaves of the green curtain and measured their fresh weight using an electronic weighting scale. We prepared five bags, and approximately 50 leaves were randomly sampled for five bags (257 leaves total). The fresh weight of each bag was measured and average individual leaf weight was calculated. Each leaf was also read by a scanner, and the length, width, and individual leaf area were measured using the LIA32 analysis software. The fresh weight of all the leaves was divided by the average individual leaf weight, and the number of leaves in the green curtain on November 4 was estimated to total 1466 . We performed simple regression analysis between leaf width $\times$ leaf length and individual leaf area, based on the 322 leaves (i.e., the 65 sampled on the seventh floor on September 13 and the 257 randomly selected on November 4 ). As a result we obtained a regression line shown by the following equation:

$$
L A_{p}=0.683 \times L I_{p} \times L W_{p},
$$

where $L A_{p}$ is the individual leaf area of leaf $p\left(\mathrm{~cm}^{2}\right)$, $L l_{p}$ is leaf length $(\mathrm{cm})$, and $L w_{p}$ is leaf width $(\mathrm{cm})$. The coefficient of determination was $R^{2}=0.98$. ${ }^{* *}$ The average individual leaf area determined from the 322 leaf samples was $72.41 \mathrm{~cm}^{2}$. To estimate the leaf area on the sixth floor, for which only the leaf length and width were measured, we calculated the individual leaf area $L A P_{i}\left(\mathrm{~cm}^{2}\right)$ of all the leaves in the frame from Eq. (1).

\section{Analysis Methods}

\subsection{Calculation of water consumption by the wall- greening plants}

The water balance of the planter box with plants is expressed by the following equation:

$$
W_{p}+W_{i}-W_{p e r}-E T_{a}-\Delta W_{s}-\Delta W_{v}=0,
$$

where $W_{p}$ is the amount of precipitation entering the planter box and $W_{i}$ is the amount of irrigation water supplied to the planter box. $W_{\text {per }}$ is the amount of water exchanged between the cistern and the rhizosphere, in which, if positive, it represents the amount of infiltra- tion, and if negative, the amount of absorption. $E T_{a}$ is evapotranspiration, $\Delta W_{s}$ is the change in the amount of moisture in the soil, and $\Delta W_{v}$ is the change in the moisture content of the plants (in $\mathrm{m}^{3} \mathrm{~h}^{-1}$ ). All elements were aggregated on an hourly basis:

$$
W_{p}=P \times A p,
$$

where $P$ is the amount of precipitation $\left(\mathrm{m} \mathrm{h}^{-1}\right)$ measured on the sixth floor terrace, and $A p$ is the surface area of the soil in the planter box $\left(=0.27 \mathrm{~m}^{2}\right)$ :

$$
W_{i}=\Delta h t \times A t,
$$

where $\Delta h t$ is the change in the depth of water depth in the irrigation water supply tank $\left(\mathrm{m} \mathrm{h}^{-1}\right)$, and $A t$ is the surface area of the supply tank. At was calculated by measuring the change in water level when weighed with a 1-L graduated cylinder until there no water remained in the tank:

$$
\begin{aligned}
& W_{p e r}=\Delta h p \times A p, \\
& \Delta W_{s}=\Delta \theta_{s} \times V_{s},
\end{aligned}
$$

where $\Delta h p$ is the change in the water level of the cistern in the planter box $\left(\mathrm{m} \mathrm{h}^{-1}\right) . \Delta \theta_{s}$ is the change in the volumetric water content of soil in the planter box, and $V_{s}$ is the volume of soil in the planter box $\left(\mathrm{m}^{3}\right)$. The amount of water consumption by the plants was determined from the residual value in Eq. (2).

$$
W_{r}=\left(\Delta W_{v}+E T_{a}\right) \times \frac{1000}{A p},
$$

where $W_{r}$ is the water consumption of the plants $(\mathrm{mm}$ $\left.\mathrm{h}^{-1}\right) . W_{r}$ was calculated every hour by determining the residual value, which was then subtracted from each measured value from Eq. (2). In this study, the daily water consumption $W_{r, d a y}\left(\mathrm{~mm} \mathrm{day}^{-1}\right)$ was defined as the sum of $W_{r}$ during a period of $24 \mathrm{~h}$ for which the beginning of the day was set at 6 am.

\subsection{Calculation of leaf areas in the green curtain}

For 4 days (August 9, August 23, September 28, and October 11) on the sixth floor, and for September 13 on the seventh floor, the total leaf area per planter box was calculated from the following equation:

$$
L A P_{\text {day }, F}=\sum_{p} L A_{\text {day }, p} \times \frac{1}{(30)^{2}} \times A G W \times \frac{5}{38},
$$

where $L A P_{d a y, F}$ is the total leaf area $\left(\mathrm{m}^{2}\right)$ per planter box on the $\mathrm{F}^{\mathrm{th}}$ floor on each day. $A G W$ is an area of the 
green curtain $\left(15.26 \mathrm{~m}^{2}\right)$. For $5 / 38$ on the right-hand side, the numerator, 5 is the number of plants in each planter box, and the denominator, 38, is the total number of plants in the experiment. The vines of most of the morning glories reached the topmost part of the net fixed on the railing of the seventh floor terrace in early August and later branched laterally along the railing. Vegetation had flourished uniformly by August 9, and the total leaf area per planter box $L A P_{A u g ~ 09, G W}\left(\mathrm{~m}^{2}\right)$ in the entire green curtain (including the seventh floor) was assumed to be equal to $L A P_{\text {Aug 09, } 6}\left(=1.78 \mathrm{~m}^{2}\right)$. By contrast, the average individual leaf area (72.41 $\mathrm{cm}^{2}$ ) multiplied by the total number of leaves in the green curtain on November 4 was estimated to be $10.62 \mathrm{~m}^{2}$. The total leaf area per planter box in the entire green curtain was $L A P_{\mathrm{Nov} 04, \mathrm{GW}}=1.40 \mathrm{~m}^{2}$.

Given that the morning glories grew more on the seventh-floor area than on the sixth-floor area after August 10, we decided to calculate the total leaf area using the following equation by dividing the total area by the height of the net on both floor.

$$
L A P_{d a y, G W}=L A P_{d a y, 6} \times \frac{339.5}{424}+L A P_{d a y, 7} \times \frac{84.5}{424},
$$

where $L A P_{d a y, G W}$ is the total leaf area $\left(\mathrm{m}^{2}\right)$ per planter box on a given date. Based on $L A P_{\text {Nov } 04, G W}=1.40 \mathrm{~m}^{2}$ and by iterative approximation in Eq. (9), the total leaf area per planter box for the sixth-and seventh-floor areas was calculated to be $L A P_{\text {Nov } 4,6}=1.06 \mathrm{~m}^{2}$ and $L A P_{\text {Nov } 4,7}=2.77 \mathrm{~m}^{2}$, respectively. Furthermore, the value obtained by dividing $L A P_{d a y, ~} G W$ by the surface area of the soil was defined as the ground leaf area index, which is expressed by the following equation:

$$
L A I_{g}=\frac{L A P_{d a y, G W}}{A P},
$$

where $L A I_{g}$ is the ground leaf area index. In general, the leaf area index $L A I_{g}$ is equal to the leaf area index ( $L A I)$. The purpose of using $L A I_{g}$ here was to distinguish it from $L A I$, which was used as the leaf area per unit of building wall area in related research (Takayama et al., 2011; Takayama et al., 2012) that discussed quantifying the effect of reducing the heat load by wall greening

\subsection{Calculation of the reference evapotranspiration and water consumption}

In general, the water consumption of greening plants is mainly determined by climatological factors and the degree of plant growth. We examined the relationship between daily water consumption and some climatological factors or $L A I_{g}$. In this study, the daily mean values for wind speed, air temperature, relative humidity, and volumetric soil water content, as well as the daily cumulative solar radiation at the wall were discussed as climatological factors. These factors can have a direct or indirect impact on water consumption according to the physiological responses of plants. In this section, we thus propose the use of the waterconsumption rate of the plants to analyze the degree of contribution of each climatological factor.

First, on the basis of periodic meteorological data from the Osaka District Meteorological Observatory, the reference evapotranspiration was calculated using the Food and Agricultural Organization (FAO) Penman-Monteith Equation (Richard et al., 1998). Reference evapotranspiration is defined as an imaginary value from a sufficiently wet surface with a grass height of $0.12 \mathrm{~m}$, under the condition that transport resistance is $70 \mathrm{~s} \mathrm{~m}^{-1}$ and average reflectance is $\alpha=$ 0.23 . The reference surface is roughly equivalent to a uniform turf surface with both a level height and sufficient growth and moisture.

$$
\begin{aligned}
E T_{0}= & \frac{0.408 \Delta\left(R_{n}-G\right)+\gamma \frac{900}{T+273} u_{2}\left(e_{s}-e_{a}\right)}{\Delta+\gamma\left(1+0.34 u_{2}\right)}, \\
R_{n}=(1-\alpha) R_{s}-R_{n l} & \\
R_{n l}= & \sigma\left[\frac{T_{\max , K}^{4}+T_{\min , K}^{4}}{2}\right]\left(0.34-0.14 \sqrt{e_{a}}\right), \\
& \times\left(1.35 \frac{R_{s}}{R_{s 0}}-0.35\right)
\end{aligned}
$$

$$
R_{s 0}=\left(0.75+2 \times 10^{-5} \cdot z\right) \cdot R_{a}
$$

where $E T_{0}$ is the reference evapotranspiration (mm day $^{-1}$ ), $R_{n}$ is net radiation, $R_{s}$ is solar radiation, $R_{s 0}$ is clear-sky solar radiation, $R_{a}$ is extraterrestrial radiation (in $\mathrm{MJ} \mathrm{m}{ }^{-2}$ day $^{-1}$ ), $z$ is elevation above sea level of the observational station $(23 \mathrm{~m}), G$ is soil heat flux $(0 \mathrm{MJ}$ $\mathrm{m}^{-2}$ day $\left.^{-1}\right), \gamma$ is the psychrometer constant $\left(\mathrm{kPa}{ }^{\circ} \mathrm{C}^{-1}\right), T$ is daily mean temperature $\left({ }^{\circ} \mathrm{C}\right)$ at $2 \mathrm{~m}$ above ground, $u_{2}$ is wind speed $\left(\mathrm{m} \mathrm{s}^{-1}\right)$ at $2 \mathrm{~m}$ above ground, $e_{s}$ is the saturation vapor pressure $(\mathrm{kPa}), e_{a}$ is water vapor 
pressure $(\mathrm{kPa})$, and $\Delta$ is the slope $\left(\mathrm{kPa}{ }^{\circ} \mathrm{C}^{-1}\right)$ of the water vapor pressure curve. The daily water consumption $W_{r, \text { day }}$ was defined in Section 3.1. The ratio of $W_{r, \text { day }}$ to the reference evapotranspiration $E T_{0}$ is defined as the daily water consumption rate and is expressed as follows:

$$
W R_{\text {day }}=\frac{W_{r, d a y}}{E T_{0}},
$$

where $W R_{d a y}$ is the water consumption rate of the plants.

The degree of contribution of climatological factors to water consumption of greening plants may be separated using $W R_{\text {day }}$, because the reference evapotranspiration is theoretically dependent only on weather conditions. Based on our analysis, we will discuss the climatological factors that dominated the water consumption of greening plants, and select the factors that should be considered as explanatory variables in order to estimate water consumption.

\section{Results and Discussion}

\subsection{Growth of the wall-greening plants}

Figure 3 (a-d) shows the wall-greening vegetation grown on the south wall of Building 9 at Osaka Institute of Technology, Omiya Campus. Ivy morning glories were in their growth stage from July to September and entered a period of decline after October. Vegetation of the green curtain aged and defoliated from the lower section of the wall (Fig. 3 (d)). The ivy morning glory used as the model plant was biennial, though various environmental stresses such as drying and poor nutrition triggered flowering and gradual decay. Figure 4 shows the total leaf area per planter box of the entire green curtain (sixth and seventh floors). It can be seen from the Fig. 4 that the leaf area began to decline in the sixth floor area by October. Considering these growth conditions of the wall-greening plants, we defined the period from August 9 to September 28 as the growth period, while the period from September 29 to November 4 was defined as the declining period. The total leaf area per planter box in the entire green curtain was then calculated using the following procedures.

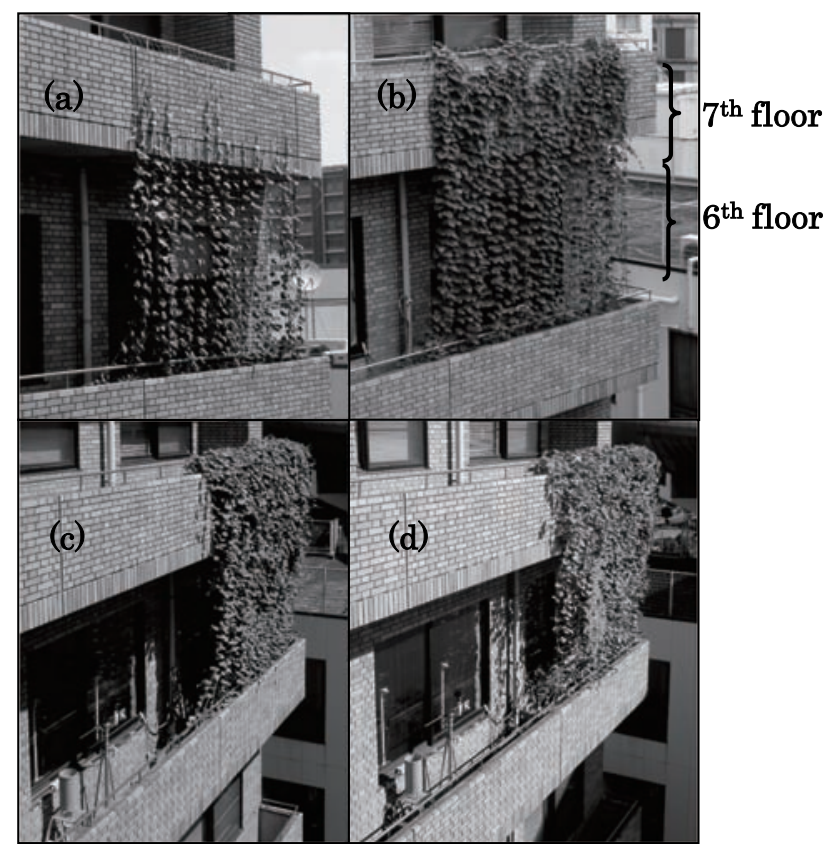

Fig. 3. Wall-greening vegetation that was grown on the south wall of Building 9 at Osaka Institute of Technology, Omiya Campus. Ivy morning glories in the growth stage from July to September (a-c). In the declining period after October vegetation of the green curtain aged and defoliated from the lower section of the wall (d). 
For the total leaf area per planter box on the sixth floor, the data plotted in Fig. 4 were interpolated with a weighted average. By contrast, since measured data were only obtained on September 13, leaf area on the seventh floor continued to increase during the growth period at the daily average rate from August 9 to September 13, after which it gradually decreased at a constant rate during the declining period, and eventually settled at the value recorded on November 4 . The leaf area per planter box in the entire green curtain was calculated from Eq. (9). The leaf area per planter box for the sixth and seventh floors, both individually and combined, are shown in Fig. 4.

\subsection{Water consumption by the wall-greening plants}

Figure 5 shows the change in daily water consumption of the green curtain from August 20 to October 12. Because the five planter boxes and 13 gardening pots each had a soil surface area of $0.27 \mathrm{~m}^{2}$ and $0.06 \mathrm{~m}^{2}$ respectively, the total surface soil area of the green wall was $2.17 \mathrm{~m}^{2}$. The daily water consumption in-

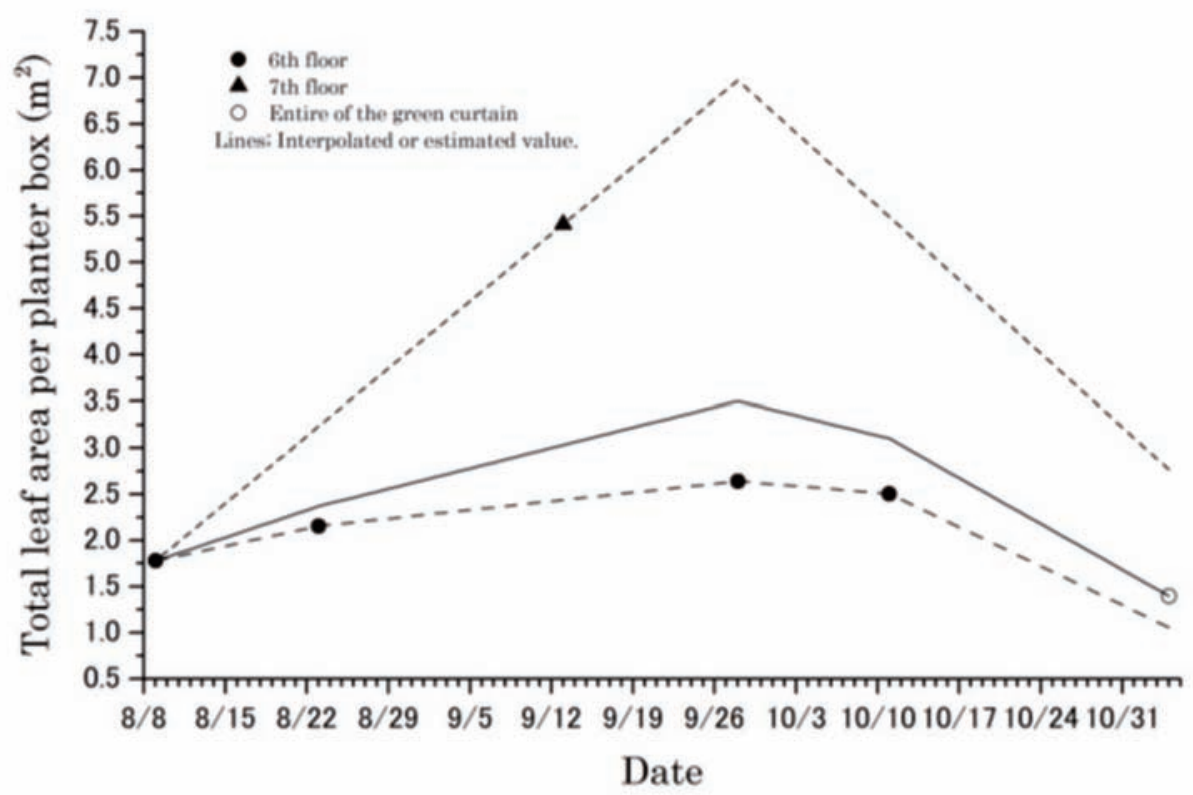

Fig. 4. The measured total leaf area per planter box of the entire green curtain, the 6th floor and 7th floors.

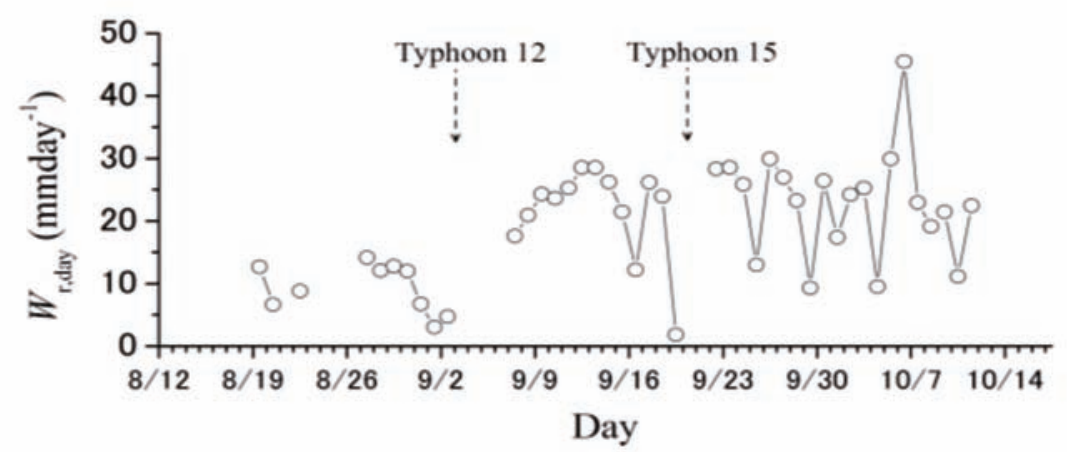

Fig. 5. The change in daily water consumption of the green curtain from August 20 to October 12, 2011. 
creased gradually until early September, after which it stabilized with slight fluctuations. The median daily water consumption by the green curtain after September 8 was $23.9 \mathrm{~mm}(51.9 \mathrm{~L})$.

Figure 5 shows that the daily water consumption decreased rapidly on September 2, 17, 20, 26, and 30, as well as on October 5 and 11. Figure 6(a) and (b) show the changes in daily mean air temperature and relative humidity during the experimental period. According to the weather report, 2 and 20 tended to have higher relative humidity due to an approaching typhoon (i.e., Typhoon No. 12 and No. 15). Figure 7 shows the daily changes in the water consumption rate of the plants and that the daily water consumption rate
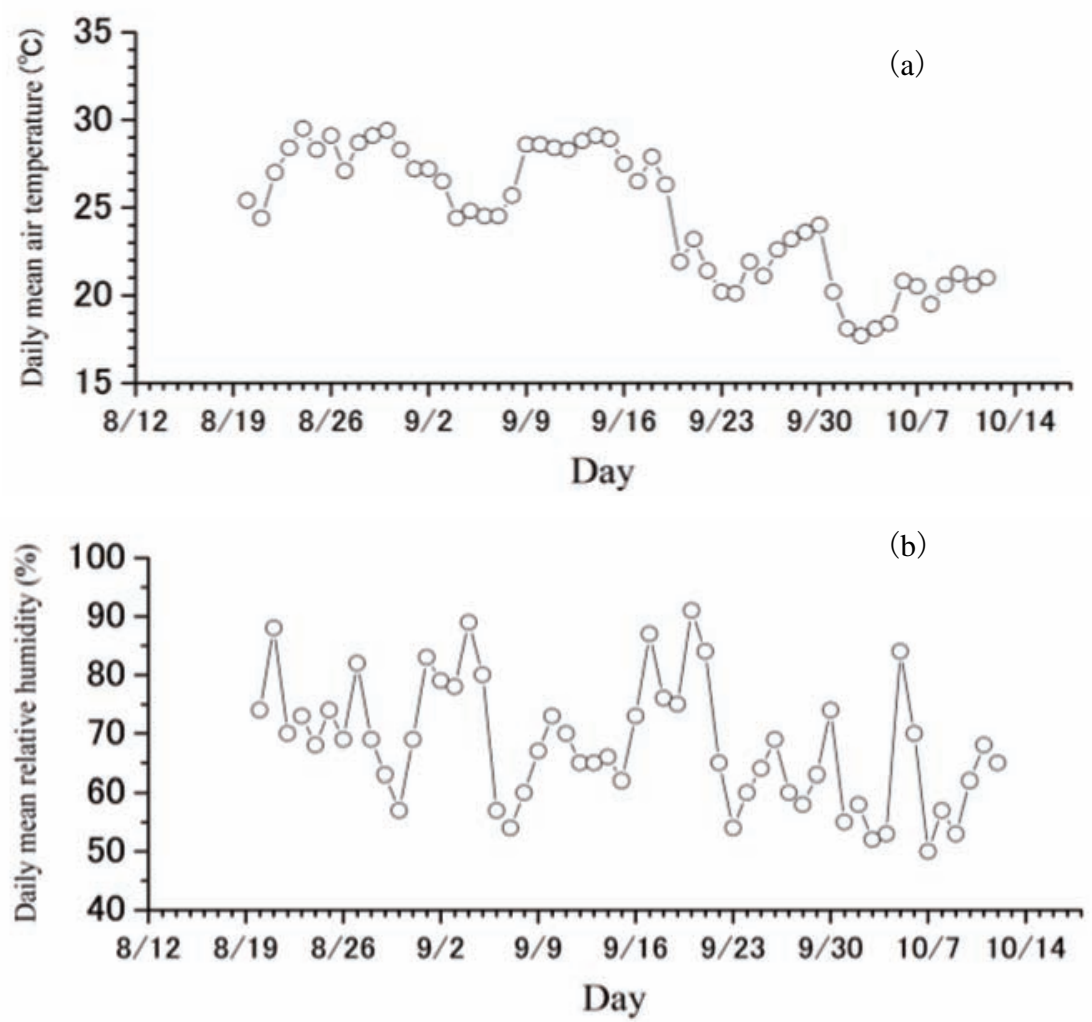

Fig. 6. Change in daily mean air temperature (a) and relative humidity (b).

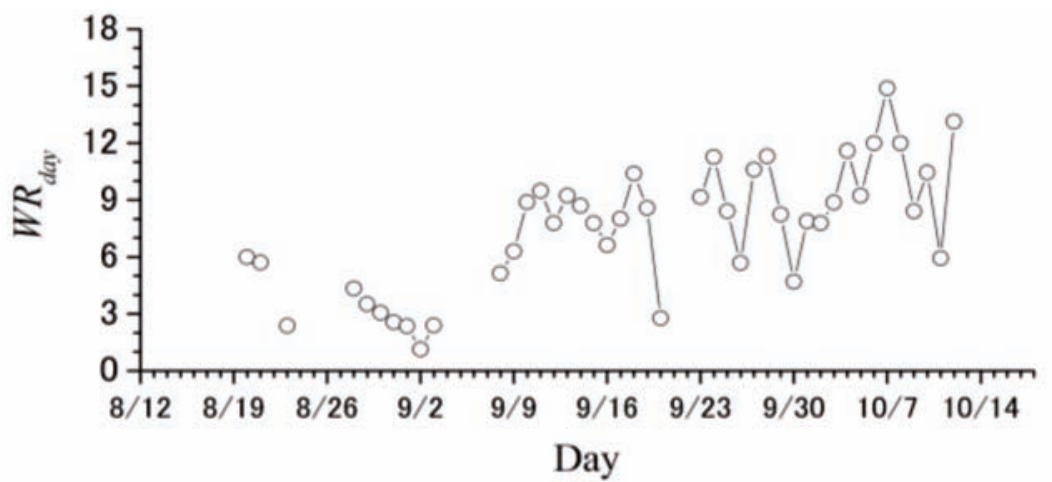

Fig. 7. Daily changes in water consumption rate of the plants. 
$\left(W R_{d a y}\right)$ exhibited an increasing trend during the experimental period. This increase was due to the fact that, while the reference (i.e., potential) evapotranspiration determined only by weather conditions, decreased with the changing seasons, the amount of water consumption remained constant. It was found that the daily water consumption rate decreased rapidly on September 26 and 30 and October 11, as well as on September 2 and 20 when the typhoon approached the Kansai region (Fig. 7). The maximum value of the daily water consumption rate during this experimental period was 14.88 on October 7. This day was a clear day dominated by migratory highs, as well as the driest day during the experimental period, with a daily mean relative humidity of $50 \%$ (Osaka District Meteorological Observatory).

4.3 Factors that dominate water consumption of greening-wall plants

As mentioned in Section 4.2, the daily maximum water consumption rate of the plants was 14.88 . The maximum value for the daily water consumption rate of the green curtain using ivy morning glories from summer to fall was therefore set to 15 , and the standard water consumption rate was defined as follows:

$$
W S R_{\text {day }}=W R_{\text {day }} \times \frac{1}{15},
$$

where $W S R_{\text {day }}$ is the standard water consumption rate with a value from 0 to 1 . In this section, we shall discuss the factors that dominated the amount of water consumed by plants (i.e., vegetation) of the green curtain and the selection of climatological factors that should be considered as explanatory variables in order to estimate the amount of water consumption. Figure 8 shows the relationship between each climatological factor or $L A I_{g}$ and the daily water consumption rate of the plants. Figure 9 shows the reference evapotranspiration.

As shown in Figs 8 and 9 (a) and (b), the wind speed and volumetric water content of the soil both were negatively correlated with $W S R_{d a y}$, though they had no correlation with $E T_{0}$. From August 31 to September 3 , the mean daily wind speed was greater than the other days on the sixth-floor terrace due to the approaching typhoon, but the $W S R_{d a y}$ had become smaller. According to Suzuki et al. (2007), who studied evaporation characteristics using green panels for wall greening, the rate of mass transfer indicating the amount of water displacement per unit of time increased logarithmically with respect to wind speed. However, plants suppress evapotranspiration when they experience stress such as water deficiency in order to retain moisture (Yamada et al., 2006). Moreover, the daily mean wind speed had no correlation with other climatological factors. So, the results of this experiment suggest the possibility that the plants actively suppressed their water consumption due to stress under conditions of exposure to strong winds (e.g., from a typhoon) in the outdoor green wall. Furthermore, the volumetric water content of the soil similar to wind speed showed a negative correlation with $W S R_{\text {day }}$. However, we cannot deny the possibility that the volumetric water content of soil correlated positively with $W S R_{\text {day }}$ from the viewpoint of soil-plant water potential, possibly due abundant soil moisture under the experimental conditions. Studies that include growing wallgreening plants under drier conditions are thus necessary for future research. In this study, these climatological factors were considered to be dominant in the water consumption of wall-greening plants given the physiological responses of the plant.

As seen in Figs 8 and 9(c) and (d), temperature and relative humidity were correlated with $E T_{0}$, but had a low or no correlation with $W S R_{\text {day }}$. We reasoned that these climatological factors act only as driving forces for water consumption of greening plants. Particularly, relative humidity acts as a dominant climatological factor for $E T_{0}$ but had a low correlation with $W S R_{\text {day }}$. The relationship between relative humidity and $E T_{0}$ is linear, meaning that the factor of relative humidity acts directly to drive plant water consumption. By contrast, part of water consumption caused by physiological factors not uniquely determined by the degree of atmospheric wetness also might be determined in combination with other climatological factors such as wind speed.

From Figs 8 and 9 (e), solar radiation on the wall surface had a positive correlation with both $E T_{0}$ and $W S R_{d a y}$. During the daytime, most of the energy for evaporation is provided by solar radiation. Moreover, water consumption might be increased to promote transpiration in order to induce vigorous photosynthesis, under the conditions of an adequate solar radiation, soil moisture, and temperature. Thus, solar radiation on the wall surface was considered to be a climatological factor. 

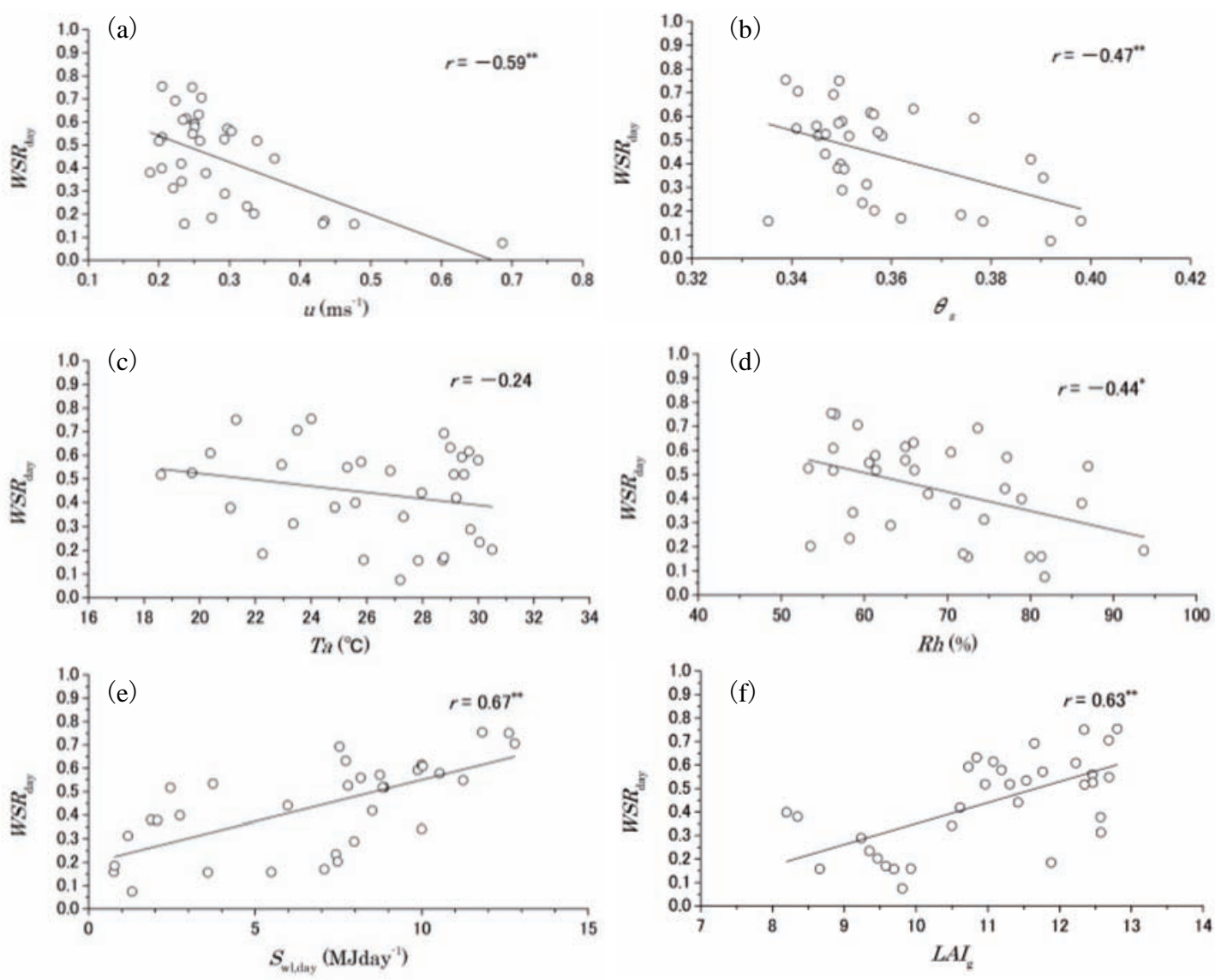

Fig. 8. The relationship between some climatological factors or $L A I_{\mathrm{g}}$ and $W S R_{d a y}$. (a) Daily mean wind speed; (b) Daily mean volumetric water content of the soil; (c) Daily mean air temperature; (d) Daily mean relative humidity; (e) Daily integrated solar radiation on the wall surface; (f) Ground leaf area index of the plants $\left(L A I_{g}\right)$. ** $99 \%$ level of significance.

Finally, from Figs. 8 and 9(f), the ground leaf area index of the plants was positively correlated with only $W S R_{\text {day, }}$, suggesting that the amount of water consumption increased due to plant growth. Therefore, the $L A I_{g}$ for the ivy morning glories in the green curtain was selected as an explanatory variable.

\subsection{Estimation of water consumption by wall green- ing}

In Section 4.3, we discussed the climatological factors that act dominantly on water consumption by wallgreening plants. In this section, we examine the model for estimating water consumption of the green curtain by ivy morning glories, which apply the factors selected in Section 4.3 as explanatory variables. Setting the standard water consumption rate as an objective varia- ble, the estimated value was calculated by multiplying the independent functions with respect to the four explanatory variables as shown in the following equation:

$$
W S R_{\text {day }}=f(u) \cdot g\left(\theta_{s}\right) \cdot h\left(S_{w l, d a y}\right) \cdot i\left(L A I_{g}\right),
$$

Each variable on the right-hand side has a value ranging from 0 to 1 . We assume that each variable acts independently for water consumption and is expressed as follows:

$$
y=\frac{A_{1}-A_{2}}{1+\left(\frac{x}{x_{0}}\right)^{p}}+A_{2},
$$

where $y$ is the calculated value of each function, $x$ is the value of each explanatory variable, and $A_{1}$ and $A_{2}$ 

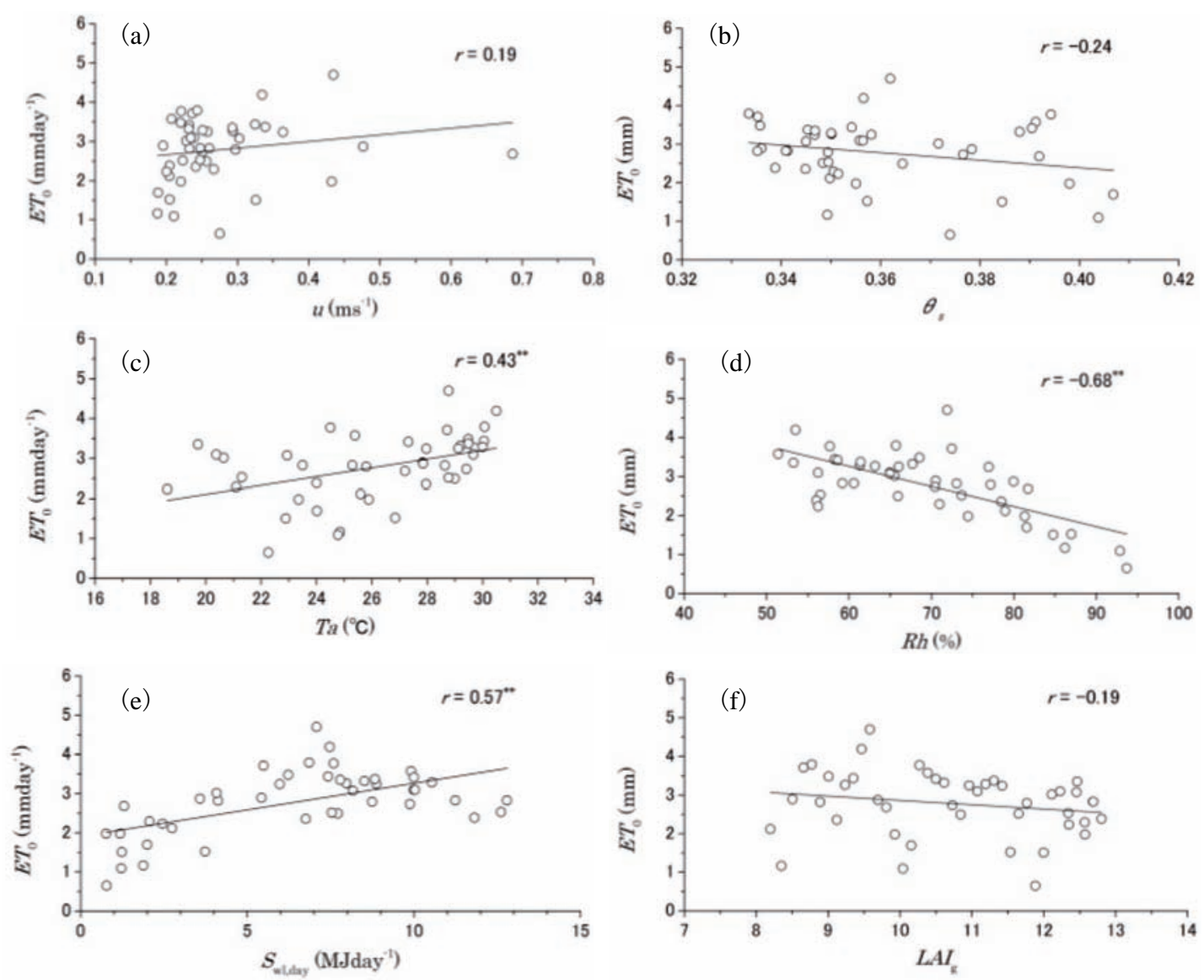

Fig. 9. The relationship between some climatological factors or $L A I_{\mathrm{g}}$ and $E T_{0}$. (a) Daily mean wind speed; (b) Daily mean volumetric water content of the soil; (c) Daily mean air temperature; (d) Daily mean relative humidity; (e) Daily integrated solar radiation on the wall surface; (f) Ground leaf area index of the plants $\left(L A I_{g}\right)$. ** $99 \%$ level of significance.

are constants. For wind speed $f(u)$ and volumetric water content $g\left(\theta_{s}\right)$, the constants were set as $A_{1}=1$ and $A_{2}=0$. For daily solar radiation on the wall $h\left(S_{\text {wlday }}\right)$ and ground leaf area index $i\left(L A I_{g}\right)$, the constants were set as $A_{1}=0$ and $A_{2}=1$. For all days on which $W S R_{\text {day }}$ could be calculated during this experiment, selected factors were applied into Eq. (17), and function parameters $x_{0}$ and $p$ were calculated to minimize the square of the error.

Table 1 shows the function parameters of each explanatory variable obtained through the iterative approximation. The absolute mean error $(M A E)$ for the estimated values against the measured values was 0.061 . Based on the estimated value of $W S R_{d a y}$, the daily water consumption can be obtained from the following equation:

$$
W_{r, \text { day }}=15 \times W S R_{\text {day }} \times E T_{0} .
$$

Figure 10 shows the change in the measured and actual values for daily water consumption. The average value for daily water consumption from August 19 to October 2 that could achieve the estimated value was 18.4 mm day ${ }^{-1}$. Because the total surface soil area of the planter boxes and gardening pots was $2.17 \mathrm{~m}^{2}$, the amount of water consumed by the green curtain during the experimental period was estimated to be $1796 \mathrm{~L}$ $\left(1.8 \mathrm{~m}^{3} ; 18.4 \mathrm{~mm} \times 2.17 \mathrm{~m}^{2} \times 45\right.$ days $)$. Additionally, the average ground leaf area index $L A I_{g}$ during the same period was 11.0 and was equivalent to approximately 11 times the area of the planting soil surface. 
Table 1. Function parameters of the 4 factors obtained through iterative approximation.

\begin{tabular}{lcrcc}
\hline & \multicolumn{1}{c}{$u$} & \multicolumn{1}{c}{$\theta_{s}$} & $S_{W I, d a y}$ & $L A I_{g}$ \\
\hline$X_{0}$ & 0.379 & 0.395 & 1.312 & 8.910 \\
$p$ & 3.115 & 67.026 & 1.341 & 5.971 \\
$A_{1}$ & 1.000 & 1.000 & 0.000 & 0.000 \\
$A_{2}$ & 0.000 & 0.000 & 1.000 & 1.000 \\
\hline
\end{tabular}

On August 23, the day when the error between the estimated and measured values reached its maximum, a heavy rain had occurred due to a stationary front in the whole of Japan. According to the records of the Osaka District Meteorological Observatory, the weather in Osaka was cloudy and the rainfall was $1.5 \mathrm{~mm}$. However, the daily mean wind speed was slightly high at $2.5 \mathrm{~m} \mathrm{~s}^{-1}$. In addition, on August 30 and 31, when the daily mean wind speeds were 3.1 and $5.0 \mathrm{~m} \mathrm{~s}^{-1}$ respectively, there was a large error in the estimation of daily water consumption. We suggest that this discrepancy requires further investigation under high-wind conditions. However, after September, when the plants had completed their growth, the values estimated from the model approximately reflected the observed values, which confirmed the effectiveness of the method proposed in this study.

\section{Conclusion}

In this study, water consumption by a climbing-type south-facing green wall using ivy morning glory was assessed. During the experimental period from August 19 to October 2, leaf area grew on average about 11 times greater than the planting area. The estimated daily mean value of water consumption was $18.4 \mathrm{~mm}$ day $^{-1}$. When the ratio of water consumption to reference evapotranspiration was defined as the water consumption rate, which was dominated by the physiological responses of plants to environmental changes, the maximum value for the water consumption during the same period was about 15 .

We proposed an estimation model using climatological factors (i.e., daily mean wind speed, daily mean volumetric water content of the soil, and daily integrated solar radiation on the wall) as well as the ground leaf area index as explanatory variables. The absolute mean error for the estimated values of the model against the observed values of daily water consumption was $M A E=0.061$. Desirable results were obtained with an estimation error of $6.1 \%$. It was found that, by studying the water consumption of plants using a water-storing cistern-type planter box, water consumption by wall-greening plants can be quantitatively analyzed.

In recent years, various plant species have begun to be used for wall greening from the standpoint of the design of urban green space, which means that the quantitative assessment of water consumption during

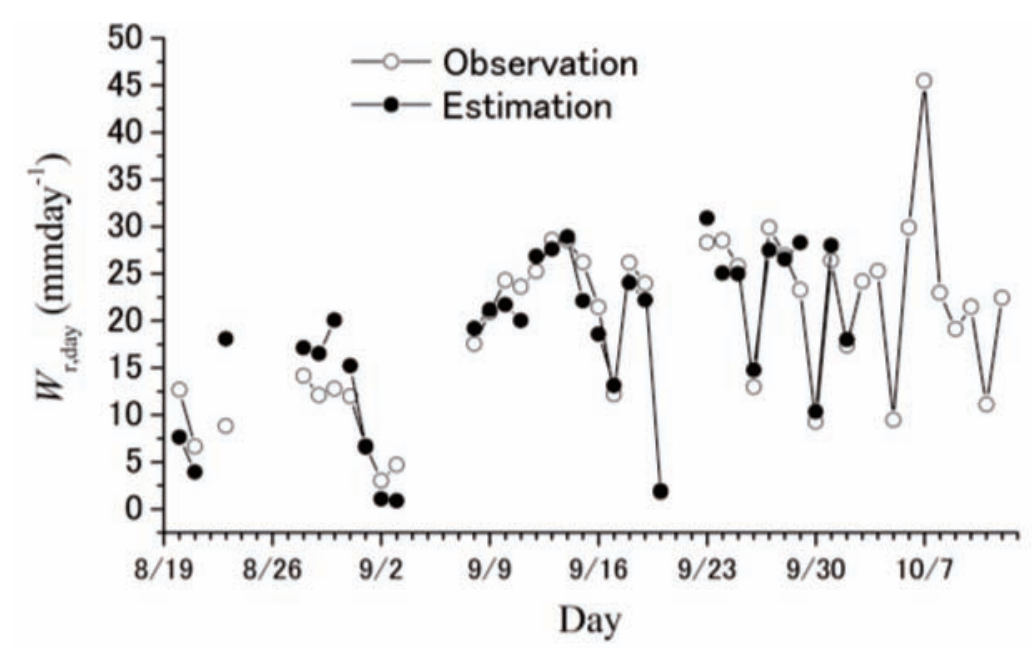

Fig. 10. Difference between measured and actual values for daily water consumption. 
these plants' growth is important. In the future, we plan to consider proposing a more robust and reproducible model in which the water consumption of various plant species can be calculated from environmental factors.

\section{Acknowledgments}

This study was conducted in accordance with: the Heisei 21-23 (2009-2011) grant project on housing and construction related technology development by Ministry of Land, Infrastructure and Transport. "Development of assessment on heat and water balance to quantify the effects of energy saving and improvement on thermal load by rainwater-harvesting wall greening"; Heisei 23 (FY 2011) Grant-in-aid for young scientists (B) "Development of technology for heat load reduction by assessment of heat and water balance to maximize the energy-saving effects of greening buildings, project number 23760552”; “The development of visualization technology using balance assessment of heat and water for the purpose of energysaving and improving heat environments by rainwaterharvesting-type wall greening" supported by the research grant from the 19th meeting of TOSTEM Foundation for Construction Materials Industry Promotion, 2010.

\section{References}

Ministry of Land, Infrastructure, Transport and Tourism, 2011: Efforts to Adapt to Climate Change on Water Resources in Japan. In Water Resource of Japan digest version of 2011 edition. (available at http://www.mlit.go.jp/common/000160790.pdf) (in Japanese) (accessed on Feb. 20 2013).

Ministry of Land, Infrastructure, Transport and Tourism, 2012: A new roof and wall greening space has been created. In Results of roof and wall greening national survey construction in 2011. (available at http://www.mlit.go.jp/common/000226442.pdf）（in Japanese) (accessed on Feb. 20 2013).

Richard, G. A., Luis, S. P., Dirk, R., and Martin, S., 1998: Crop Evapotranspiration (guidelines for Computing Crop Water Requirements). In FAO IRRIGATION AND DRAINAGE PAPER No. 56, FAO, 300pp.
Suzuki, H., Kojima, T., Shimada, S., Nojima, Y., and Tashiro, Y., 2005: The trend and tasks of the technology development on the wall greening, Journal of Japan Society of Revegetation Technology, 31, 247-259.

Suzuki, H., Misaka, I. and Tashiro, Y., 2007: Evaluation of Transpiration Properties of wall Greening Using Evaporation Efficiency Rate as an Index, Landscape Research Japan, 70, 401-406.

Takayama, N., Kawamura, K., Yamamoto, H., Nobori, S., and Tominaga, Y., 2012: The water consumption of plants by south wall greening using vine ivy morning glories, Journal of Agricultural Meteorology, Kinki branch, 5, 16-21.

Takayama, N., Yoshikoshi, H., Yamamoto, H., Iwaya, K., Harada, Y. and Yamasaki. T., 2011: Quantitative Evaluation of Mitigation Effect for Thermal Load of Solar Radiation through the Glass Window by Wall Greening, Journal of Environmental Engineering (Transactions of Architectural Institute of Japan), 76, 247-254.

Todo, K., Ogura, D., Hokoi, S. and Kotani. H., 2008: Reduction of Thermal Impacts on Indoor and Outdoor Environment by Greening Walls, Journal of Environmental Engineering (Transactions of Architectural Institute of Japan), 73, 1109-1116.

Tokyo Metropolitan Government, 2012: Whole situation and status of "10-Year Project for Green Tokyo". In Project status of "10-Year Project for Green Tokyo", (available at http://www.kankyo.metro.tokyo.jp/nature/attacheme nt/2012fact.pdf) (in Japanese) (accessed on Feb. 20 2013).

Urban Greenery Technology Development Organization (Foundation), 1996: NEO-GREEN SPACE DESIGN, New manual for spread of green space design (2). In Special green space series, Seibundo Shinkosha, Tokyo, 237pp. (in Japanese).

Yamada, Y., Kimura, R., Sugimura, F., and Kamichika, M., 2006: Evaluation for Non-Dimensional Evapotranspiration with Radiometric Surface Temperature, Journal of Agricultural Meteorology, 62, 133-137.

Yamamoto, K., 2010: LIA for Win32 (LIA32), Version 0.378. (available at http://www.agr.nagoyau.ac.jp/ shinkan/LIA32/index-e.html) (accessed on Feb. 22 2011) . 